Article

\title{
A New Era in Engineering Plastics: Compatibility and Perspectives of Sustainable Alipharomatic Poly(ethylene terephthalate)/Poly(ethylene 2,5-furandicarboxylate) Blends
}

\author{
Dimitrios G. Papageorgiou ${ }^{1, * \mathbb{D}}$, Irini Tsetsou ${ }^{2}$, Raphael O. Ioannidis ${ }^{2} \mathbb{D}$, George N. Nikolaidis ${ }^{2} \mathbb{D}$, \\ Stylianos Exarhopoulos ${ }^{3}\left(\mathbb{D}\right.$, Nejib Kasmi $^{4}\left(\mathbb{D}\right.$, Dimitrios N. Bikiaris ${ }^{5}\left(\mathbb{D}\right.$, Dimitris S. Achilias ${ }^{5}$ \\ and George Z. Papageorgiou 2,6,*(D)
}

check for updates

Citation: Papageorgiou, D.G.; Tsetsou, I.; Ioannidis, R.O.; Nikolaidis, G.N.; Exarhopoulos, S.; Kasmi, N.; Bikiaris, D.N.; Achilias, D.S.; Papageorgiou, G.Z. A New Era in Engineering Plastics: Compatibility and Perspectives of Sustainable Alipharomatic Poly(ethylene terephthalate)/Poly(ethylene 2,5-furandicarboxylate) Blends. Polymers 2021, 13, 1070. https:// doi.org/10.3390/polym13071070

Academic Editor: Zbigniew Bartczak

Received: 8 March 2021

Accepted: 25 March 2021

Published: 29 March 2021

Publisher's Note: MDPI stays neutral with regard to jurisdictional claims in published maps and institutional affiliations.

Copyright: (c) 2021 by the authors. Licensee MDPI, Basel, Switzerland This article is an open access article distributed under the terms and conditions of the Creative Commons Attribution (CC BY) license (https:// creativecommons.org/licenses/by/ $4.0 /)$
1 School of Engineering and Materials Science, Queen Mary University of London, Mile End Road, London E1 4NS, UK

2 Chemistry Department, University of Ioannina, P.O. Box 1186, 45110 Ioannina, Greece; eirinitsetsou789@yahoo.gr (I.T.); pch01348@uoi.gr (R.O.I.); geoniknikolaidis@gmail.com (G.N.N.)

3 Department of Food Science and Technology, International Hellenic University, P.O. Box 141, 57400 Thessaloniki, Greece; stelexar@yahoo.gr

4 Department of Materials Research and Technology (MRT), Luxembourg Institute of Science and Technology (LIST), 5 Avenue des Hauts-Fourneaux, L-4362 Esch-sur-Alzette, Luxembourg; nejibkasmi@gmail.com

5 Laboratory of Polymer Chemistry and Technology, Department of Chemistry, Aristotle University of Thessaloniki, 54124 Thessaloniki, Greece; dbic@chem.auth.gr (D.N.B.); axilias@chem.auth.gr (D.S.A.)

6 Institute of Materials Science and Computing, University Research Center of Ioannina (URCI), 45110 Ioannina, Greece

Correspondence: d.papageorgiou@qmul.ac.uk (D.G.P.); gzpap@uoi.gr (G.Z.P.)

\begin{abstract}
The industrialisation of poly(ethylene 2,5-furandicarboxylate) for total replacement of poly(ethylene terephthalate) in the polyester market is under question. Preparation of high-performing polymer blends is a well-established strategy for tuning the properties of certain homopolymers and create tailor-made materials to meet the demands for a number of applications. In this work, the structure, thermal properties and the miscibility of a series of poly(ethylene terephthalate)/poly(ethylene 2,5-furandicarboxylate) (PET/PEF) blends have been studied. A number of thermal treatments were followed in order to examine the thermal transitions, their dynamic state and the miscibility characteristics for each blend composition. Based on their glass transition temperatures and melting behaviour the PET/PEF blends are miscible at high and low poly(ethylene terephthalate) (PET) contents, while partial miscibility was observed at intermediate compositions. The multiple melting was studied and their melting point depression was analysed with the Flory-Huggins theory. In an attempt to further improve miscibility, reactive blending was also investigated.
\end{abstract}

Keywords: poly(ethylene furanoate); poly(ethylene terephthalate); blends; crystallization

\section{Introduction}

Not surprisingly, over the last decade there is growing interest in the preparation of new chemicals and materials based on renewable resources; biomass-derived fuel and chemicals are a promising alternative to fossil based materials [1,2]. Generally, bio-based plastics can be manufactured via three main pathways [3]. The first pathway involves the modification of natural polymers (e.g., for production of starch and cellulose-based plastics). The second-and most important-approach involves conversion of biomass to bio-based precursors (monomers) via biochemical and/or chemical transformation followed by polymerization of the monomers. As a result, conventional monomers (dropin) and then conventional plastics, such as polyethylene (PE) or poly(ethylene terephthalate) (PET), can be produced. New monomers, especially aromatic ones, and new polymers such as poly(ethylene 2,5-furandicarboxylate) (PEF) can be also manufactured and are 
expected to have a key role in the new era of sustainable engineering plastics from biomass for the development of a biobased economy. Finally, the third approach involves polymers that can be formed from microorganisms such as (polyhydroxyalkanoates) (PHA), or from plants and finally by using $\mathrm{CO}_{2}$ as a feedstock [4-7].

2,5-furandicarboxylic acid is considered as one of the most important building blocks or top value-added chemicals derived from biomass, according to the U.S. Department of Energy $[8,9]$. FDCA can be used for the production of polyesters bearing furan moieties such as poly(ethylene 2,5-furan dicarboxylate) (PEF) and poly(butylene 2,5-furan dicarboxylate) (PBF) which can be regarded as the biobased alternatives of terephthalates [10-13]. PEF is the most important furan-based polyester as it can be formulated in films, fibers and bottles. It has been shown that PEF bottles exhibit 11 times better $\mathrm{O}_{2}$ barrier than their PET counterparts, 19 times better $\mathrm{CO}_{2}$ barrier and 1.6 times higher tensile modulus [14-16] The improved properties of PEF are related with the differences in the stiffness and the motional dynamics of the aromatic rings, which are present in the PEF structure. The hindrance of furan ring-flipping explains the significant reduction in oxygen diffusion coefficient and permeability as compared to PET. In addition, a recent investigation by dielectric spectroscopy and differential scanning calorimetry revealed the important role of the restricted amorphous fraction [17]. The latter is of key importance to the gas barrier and mechanical properties. It has also been reported that use of PEF may lead to a reduction of the non-renewable energy use of about $40 \%$ to $50 \%$ while greenhouse gas (GHG) emissions can also be lowered by about 50\%, compared to PET [18].

Poly(ethylene terephthalate) on the other hand, is the most important thermoplastic polyester in terms of its commercial value, as it used in several applications and especially in soft drink containers. The overall consumption of PET was 100 million tons in 2016 and it currently grows by $4 \%$ per year [19]. However, since the majority of the feedstocks for PET are petroleum-based, a number of potential routes have been proposed to synthesize PET monomers from biomass. Academic and industrial researchers have made significant efforts to produce $100 \%$ renewable PET by using drop-in replacements of PET precursors from biomass [20-22]. Due to its commercial importance, PET is one of the most studied polymers, hence a variety of copolymers, blends, and composites based on PET have been investigated [23-27].

The modification and functionalization of polymeric materials can be achieved with a number of strategies, including the fabrication of polymer blends. From the aspect of crystallizability of the constituents, binary polymer blends can be classified into amorphous/amorphous, crystalline/amorphous, and crystalline/crystalline systems [28]. Most of the studies on polymer blends are focused on pairs of two amorphous polymers or mixtures in which one of the components is semicrystalline. On the other hand, semicrystalline/semicrystalline polymer pairs have received less attention. It is usually more difficult experimentally to investigate the miscibility (in the amorphous phase) of blends of which both constituents are semicrystalline polymers. Miscibility is relatively rare in polymer pairs because of the entropy of mixing for high molecular weight chains [29,30]. For PET, blending with other polymers to improve gas barrier properties, transparency, thermal resistance, and recyclability is of special importance for applications such as in soft drink containers. Transesterification reactions and formation of copolymers both play a crucial role in improving interfacial adhesion and homogenization in PET blends [31]. Thus, reactive blending offers another opportunity for arriving to increased compatibilization. As a number of obstacles may exist towards the industrialization of PEF, including discoloration, low thermal stability and slow crystallization compared to PET, a more careful strategy for the introduction of PEF in the marketplace and a progressive transition from PET to PEF should be drawn. It is important to point out that the two polymers, $\mathrm{PEF}$ and PET, are expected to meet in the recycling stream from municipal wastes, so the compatibility of the PET-PEF blends is of special importance.

In this work, a series of PET-PEF blends were prepared and studied by a number of characterization techniques. The presence of bio-based PEF in the produced blends 
could reduce the environmental impact from the extensive use of petroleum-originating terephthalic acid, while maintaining the recyclability of the final product. Since recent efforts on the mass production of PEF have materialized by large companies such as Avantium, the blends can be readily produced in an industrial scale. Herein, the miscibility and crystallization of the blends were studied by means of differential scanning calorimetry (DSC), temperature modulated DSC (MDSC), wide-angle X-ray diffractometry (WAXD), and polarized light microscopy (PLM). Finally, reactive blending was simulated within a DSC pan at elevated temperatures, in order to evaluate its potential as a way to achieve homogeneity in the PET-PEF blends.

\section{Experimental}

\subsection{Materials}

Dimethyl terephthalate (DMT) was obtained from Du Pont De Nemours Co. and 2,5furan dicarboxylic acid (purum 97\%) was purchased from Sigma Aldrich Co. (Darmstadt, Germany) Ethylene glycol and tetrabutyl titanate (TBT) catalyst of analytical grade were purchased also from Sigma Aldrich Co. (Darmstadt, Germany). All other materials and solvents used were of analytical grade.

\subsection{Synthesis of 2,5-Dimethylfuran-Dicarboxylate (DMF)}

For the synthesis of DMF, $15.6 \mathrm{~g}$ of 2,5-furandicarboxylic acid, $200 \mathrm{~mL}$ of methanol anhydrite and $2 \mathrm{~mL}$ of concentrated sulfuric acid was transferred into a random flask $(500 \mathrm{~mL})$ and the mixture was refluxed for $5 \mathrm{~h}$. The excess of the methanol was distilled and the solution was filtered through a disposable Teflon membrane filter. During filtration dimethylester was precipitated as white powder and following cooling, $100 \mathrm{~mL}$ of distilled water was added. The dispersion was partially neutralized by adding $\mathrm{Na}_{2} \mathrm{CO}_{3} 5 \%$ w/v during stirring while $\mathrm{pH}$ was measured continuously. The white powder was filtered and the solid was washed several times with distilled water and dried. The isolated white methylester was recrystallized with a mixture of 50/50 v/v methanol/water. Following cooling, 2,5-dimethylfuran-dicarboxylate (DMF) was precipitated in the form of white needles. The reaction yield was calculated at $83 \%$.

\subsection{Polyester Synthesis}

The polyesters were prepared by the two-stage melt polycondensation method (esterification and polycondensation) in a glass batch reactor. For the preparation of PET (Scheme 1a) the proper amounts of DMT and EG at a molar ratio of diester/EG =1/2.2 were charged into the reaction tube of the polyesterification apparatus. For the synthesis of PEF (Scheme 1b), a higher molar ratio was used (DMF/EG =1/3). TBT (400 ppm) was added as catalyst and the apparatus with the reagents was evacuated several times and filled with argon in order to remove the whole oxygen amount. The reaction mixture was heated at $190^{\circ} \mathrm{C}$ under argon atmosphere and stirring at a constant speed $(350 \mathrm{rpm})$. For the synthesis of PEF the reagents were first heated at $160{ }^{\circ} \mathrm{C}$ under argon atmosphere for $2 \mathrm{~h}$ at $170{ }^{\circ} \mathrm{C}$ for additional $2 \mathrm{~h}$ and finally at $180-190^{\circ} \mathrm{C}$ for $1 \mathrm{~h}$. This first step (transesterification) is considered to complete after the collection of almost all the theoretical amount of $\mathrm{CH}_{3} \mathrm{OH}$, which was removed from the reaction mixture by distillation and collected in a graduate cylinder.

(a)<smiles>CCCOCCOC(=O)c1ccc(C(=O)O)cc1</smiles>

(b)<smiles>CCOC(=O)c1ccc(C(=O)OCCOC(C)C)o1</smiles>

Scheme 1. The chemical structures of poly(ethylene terephthalate) (PET) (a) and PEF (b). 
In the second step of polycondensation, vacuum (5.0 Pa) was applied slowly over a period of time of about $30 \mathrm{~min}$ to remove the excess of diols and to avoid excessive foaming and furthermore to minimize oligomer sublimation, which is a potential problem during melt polycondensation. The temperature was gradually increased $(1 \mathrm{~h})$ for PET synthesis to $280{ }^{\circ} \mathrm{C}$ while stirring speed was increased at $720 \mathrm{rpm}$. The polycondensation continued for about $120 \mathrm{~min}$ at $280^{\circ} \mathrm{C}$. For PEF synthesis the temperature was slowly increased from $190{ }^{\circ} \mathrm{C}$ to $220^{\circ} \mathrm{C}$ while stirring speed was increased at $720 \mathrm{rpm}$. The reaction continued at this temperature for $2 \mathrm{~h}$ and after that time the temperature was increased to $235^{\circ} \mathrm{C}$ for $2 \mathrm{~h}$ and at $250{ }^{\circ} \mathrm{C}$ for additional $2 \mathrm{~h}$. Following the completion of the polycondensation reaction, polyesters were easily removed, milled and washed with methanol.

\subsection{Preparation of Blends}

PET and PEF samples were synthesized by applying the melt polycondensation method. Then, PET-PEF blends were prepared by using the solvent method. A mixture of Chloroform/Trifluoroacetic acid 5/1 v/v was used as the mutual solvent of the two polymers. The blends were then removed from the solution as white powder by adding excess of methanol. The samples were annealed at $160^{\circ} \mathrm{C}$ for $2 \mathrm{~h}$ prior to testing to enhance their crystallinity.

\subsection{Polyester Characterization}

\subsubsection{Wide Angle X-Ray Diffraction Patterns (WAXD)}

$X$-ray diffraction measurements of the samples were performed using a MiniFlex II XRD system from Rigaku Co, with $\mathrm{CuK}_{\alpha}$ radiation $(\lambda=0.154 \mathrm{~nm})$ in the angle $2 \theta$ range from 5 to 60 degrees.

\subsubsection{Differential Scanning Calorimetry (DSC)}

A Perkin-Elmer, Pyris Diamond DSC differential scanning calorimeter, calibrated with pure indium and zinc standards, was used. The system also included an Intracooler $2 \mathrm{P}$ cooling accessory, in order to achieve function at sub-ambient temperatures and high cooling rates. Samples of $5 \pm 0.1 \mathrm{mg}$ sealed in aluminium pans were used, to test the thermal behavior of the quenched polymers. In order to obtain amorphous materials, the samples were heated to $40{ }^{\circ} \mathrm{C}$ above the melting temperature (up to $280{ }^{\circ} \mathrm{C}$ ) and held there for $2 \mathrm{~min}$-in order to erase any thermal history-followed by rapid cooling with the highest achievable rate (nominal rate of $500{ }^{\circ} \mathrm{C} / \mathrm{min}$ and real average rate of $\sim 80{ }^{\circ} \mathrm{C} / \mathrm{min}$ down to $0{ }^{\circ} \mathrm{C}$ ). Isothermal crystallization experiments of the polymers at various temperatures below the melting point were performed. For the non-isothermal crystallization experiments, the samples were heated at temperatures higher than their equilibrium melting temperatures and then they were cooled at various cooling rates, ranging from 1.25 up to $10^{\circ} \mathrm{C} / \mathrm{min}$. With regards to reactive blending, within an industrial environment it involves melt mixing in an extruder at temperatures higher than the melting temperatures of the elements of the blend. In order to simulate reactive blending in a much smaller scale this work, the blends were initially prepared from solution, as described above, and were subsequently melt-mixed inside the DSC pans. In detail, during reactive blending, the blends were heated at a rate of $20^{\circ} \mathrm{C} / \mathrm{min}$ up to a predetermined temperature that was well above the melting points of both components, where they were held for a specific time in each test before quenching to $-30^{\circ} \mathrm{C}$. The quenched samples were subsequently heated again at $20{ }^{\circ} \mathrm{C} / \mathrm{min}$, starting from a temperature of at least $30{ }^{\circ} \mathrm{C}$ below the lower $T_{\mathrm{g}}$ of the polymers.

A TA Instruments modulated temperature DSC (MTDSC) TA Q2000, (New Castle, DE, USA) was also used for the temperature-modulated DSC measurements. The instrument was calibrated with indium for the heat flow and temperature, while the heat capacity was evaluated using sapphire standard. The sample mass was kept around $5 \mathrm{mg}$ in all tests. The Al sample and reference pans are of identical mass with an error $\pm 0.01 \mathrm{mg}$. The 
temperature modulated DSC scans (TMDSC) were performed at a heating rate of $5^{\circ} \mathrm{C} / \mathrm{min}$, with temperature modulation amplitude of $1{ }^{\circ} \mathrm{C}$ and a period of $60 \mathrm{~s}$.

The modulated DSC measurements include the introduction of isothermal steps between the heating steps and the different signals correspond to different contributions during the heating process. The non-reversing signal is known to represent the melting of stacks of lamellae or separate polymer lamellae. The reversing signal is associated to the partial melting of the lamellae which recrystallize rapidly on existing signals. It enables us to distinguish events such as the glass temperature from other non-reversing processes, such as enthalpy relaxation or recrystallization, which are absolutely not present in the non-reversing signal. For this reason, the resolution of different thermal events with the use of modulated DSC measurements is standard practice in the study of the thermal properties of polymers.

\subsubsection{Polarizing Light Microscopy (PLM)}

A polarizing light microscope (Nikon, Optiphot-2, Tokyo, Japan) equipped with a Linkam THMS 600 (Waterfield, Epsom, United Kingdom) heating stage, a Linkam TP 91 (Waterfield, Epsom, United Kingdom) control unit and also a Jenoptic ProgRes C10Plus camera (Jiena, Germany) with the Capture Pro 2.1 software was used for PLM observations.

\section{Results and Discussion}

\subsection{Primary Characterisation}

The structure of the two homopolymers, PEF and PET was initially examined by WAXD (Figure 1). For PET, the thermodynamically stable a-form appeared from the characteristic WAXD pattern, with a triclinic unit cell with $a=4.56 \AA, b=5.94 \AA, c=10.75 \AA$, $\alpha=98.5^{\circ}, \beta=118^{\circ}$, and $\gamma=112^{\circ}$ [32]. The repeating unit along the c-axis contains one monomer, with the polymer chain tilted by $\sim 5^{\circ}$ with respect to the $c$-axis. For PEF unit cell the space group is $\mathrm{P} 2{ }_{1}$, with a monoclinic unit cell where $a=5.784 \AA, b=6.780 \AA$, $c=20.296 \AA$, and $\gamma=103.3^{\circ}$. The repeating unit consists of two monomers related to each other by a $2_{1}$ screw axis $[33,34]$.

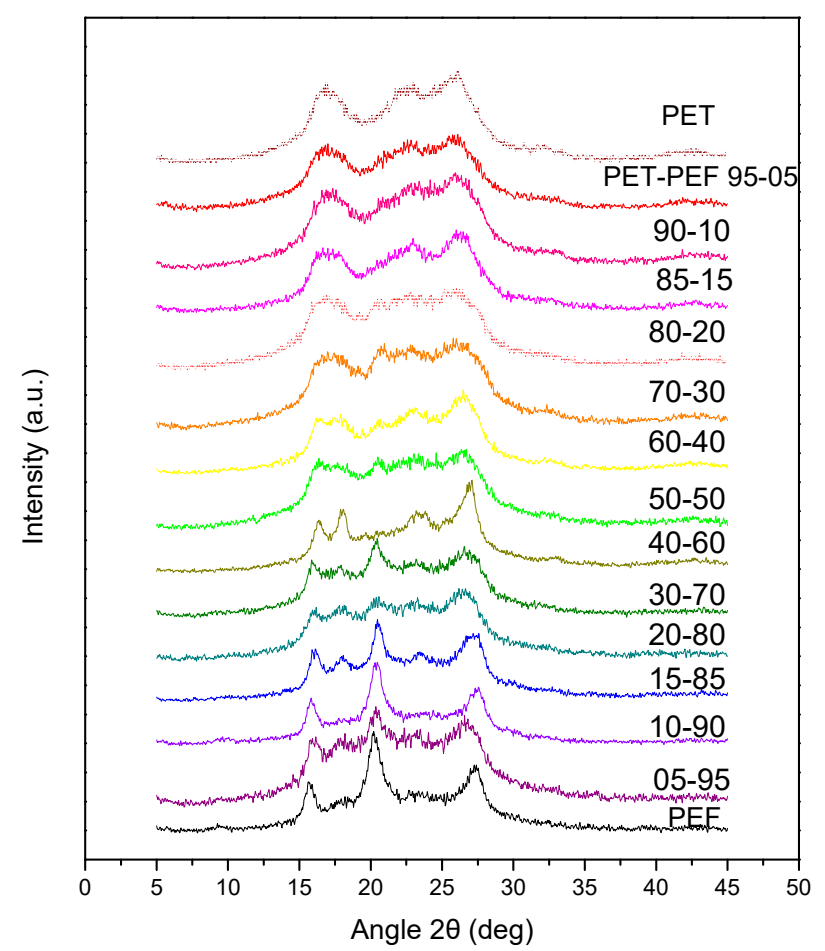

Figure 1. Wide-angle X-ray diffractometry (WAXD) patterns for the blends and for the PEF and PET homopolymers and their blends at different compositions as indicated. 
The WAXD patterns of the blends are shown in Figure 1. The peaks generally appear quite strong and pronounced, an indication of significant crystallinity, as a result of both solution crystallization and annealing procedures. Crystalline peaks for both polyesters can be detected in the patterns of the blends, especially for intermediate blend compositions. Based on this observation it can be realized that this can be considered as a crystalline/crystalline blend system [32,34,35].

The thermal transitions of the blends were studied by DSC. The DSC heating scans (at $20{ }^{\circ} \mathrm{C} / \mathrm{min}$ ) for the blends are shown in Figure 2a; melting peaks for both polymers are present, except for the PET-PEF 95-5 blend. In the thermograms of the latter, the melting of $\mathrm{PEF}$ is not clearly observed as a result of the low PEF content. A low temperature melting peak, just above $180{ }^{\circ} \mathrm{C}$ appears in all DSC thermograms, which should be associated mainly with the annealing process. Furthermore, it must be noted that for the blends, a slight decrease in the melting temperature of PET was recorded with increasing PEF content. This took place simultaneously with the reduction in the heat of fusion for the corresponding melting peaks, indicating lower degrees of crystallinity for intermediate blend compositions.
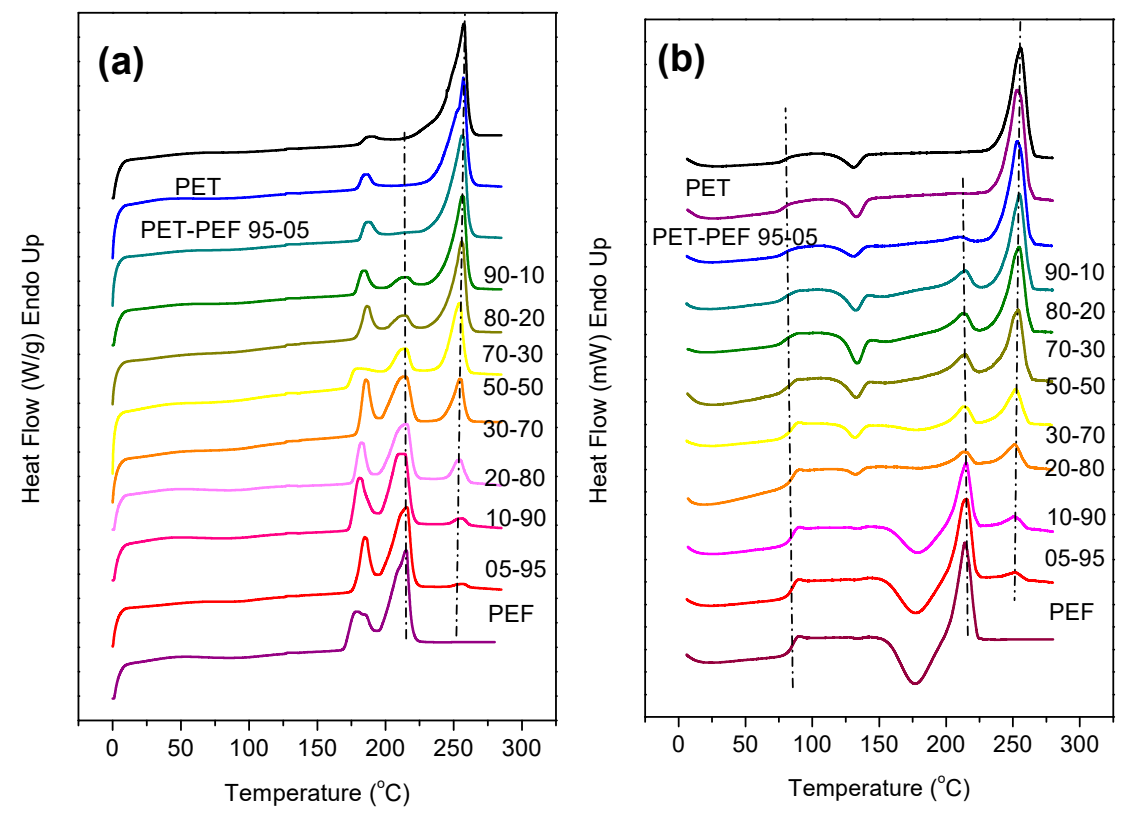

Figure 2. Differential scanning calorimetry (DSC) thermograms (a) for the semicrystalline blends recorded upon heating at $20^{\circ} \mathrm{C} / \mathrm{min}$ and (b) total Modulated Temperature DSC (MTDSC) signal for the fast-cooled samples upon heating at $5^{\circ} \mathrm{C} / \mathrm{min}$.

Figure $2 \mathrm{~b}$ shows the total signal recorded from temperature modulated-DSC experiments for the blends, at a heating rate of $5^{\circ} \mathrm{C} / \mathrm{min}$, after fast cooling at an initial rate of $80^{\circ} \mathrm{C} / \mathrm{min}$ in the DSC cell. MDSC is a powerful thermal analysis tool as it can separate reversible from non-reversible phenomena [36]. PEF is known to crystallize at relatively slow rates [37-39]. As it can be seen, only those blends with a PEF content higher than $80 \mathrm{wt} . \%$ were efficiently quenched and obtained in the amorphous state. PEF did coldcrystallize upon heating, but even cold-crystallization was suppressed with increasing the PET content beyond $10 \mathrm{wt} . \%$ in the blends. PET on the other hand crystallizes fast, so its crystallization cannot be efficiently suppressed upon cooling at a rate of $80{ }^{\circ} \mathrm{C} / \mathrm{min}$. Under these conditions, only a minor cold-crystallization peak can be detected and not pronounced cold crystallization. Melting peaks for both polymer components of the blends appeared, again with the exception of the PET-PEF 95-5 sample. The first dotted line in the figure at $\sim 80^{\circ} \mathrm{C}$ also indicates a glass temperature that will be further analyzed below. We should mention at this point the proximity of the glass temperatures for the two homopolymers: $T_{\mathrm{g}(\mathrm{PET})}=81^{\circ} \mathrm{C}$ and $T_{\mathrm{g}(\mathrm{PEF})}=88^{\circ} \mathrm{C}$. This fact makes a systematic investigation of the 
thermodynamic state with respect to miscibility for the two components in the blends, a difficult task.

The reversing signals from the MDSC curves of the blends were also studied (Figure 3a). The results showed a shift in the glass temperature region towards higher temperatures with increasing PEF content, and there were also indications for double $T_{g} s$. In the nonrevering signal curves (Figure $3 b$ ), besides the recrystallization exothermic peak in the melting temperature region, a cold-crystallization peak can be detected for PET and at slightly higher temperatures for PEF. According to Woo et al. [40], for polymer blends in which the $T_{g}$ values are very close, a single cold-crystallization peak is an indication of miscibility. Therefore, for the PET-PEF blends this prerequisite for miscibility seems that it cannot be satisfied. It should be stated though that in this work, detailed non-reversing signals recorded during slow heating scans (average heating rate $5^{\circ} \mathrm{C} / \mathrm{min}$ ) from MDSC were used, in contrast to the work of Woo et al. where only standard DSC traces recorded at a fast heating rate of $20^{\circ} \mathrm{C} / \mathrm{min}$ were analyzed [40].
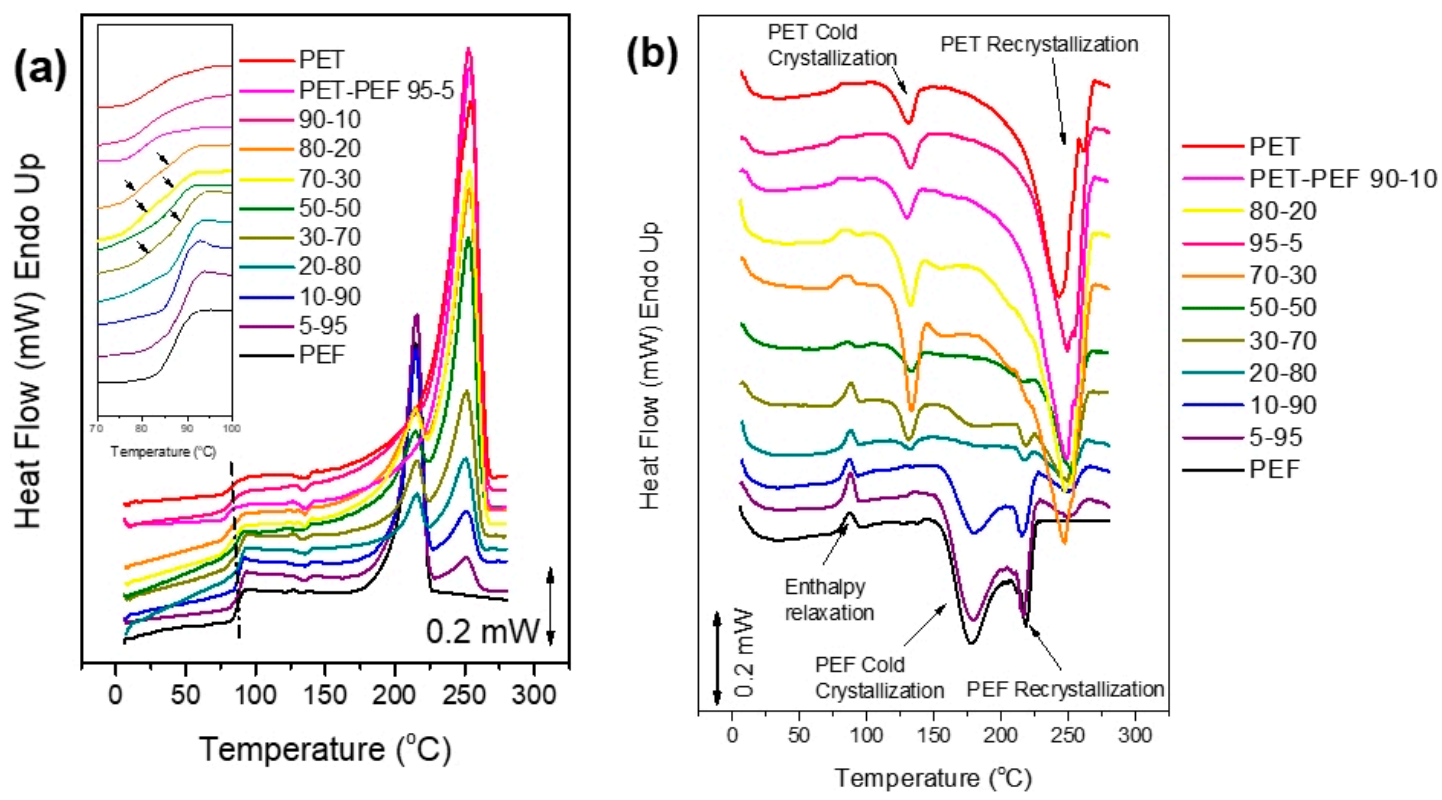

Figure 3. Modulated Temperature DSC (MDSC) thermograms for the fast-cooled upon heating at $5{ }^{\circ} \mathrm{C} / \mathrm{min}$ : (a) reversing signals and (b) non-reversing signals.

A high-sensitivity power-compensation DSC was also elaborated for the study of the glass temperatures in the blends. The samples were first melt quenched on an ice-cold metal plate. Effective quenching resulted in almost completely amorphous samples as it can be concluded from the comparison between the heat of cold crystallization and the heat of the subsequent melting during the DSC scans at $20^{\circ} \mathrm{C} / \mathrm{min}$ (Figure 4a), which were practically equal. As it can be seen in Figure $4 \mathrm{~b}$ where the details of the glass temperatures are shown, two separate glass temperatures can be seen at several compositions, as pointed out with the two arrows. The red dotted line in the figure correspond to the glass temperature of PET and the black dotted line shows the $T_{\mathrm{g}}$ of PEF. It is known that thermodynamic miscibility cannot be concluded on the basis of a dual $T_{\mathrm{g}}$ as both immiscible and miscible blends exhibit two $T_{\mathrm{g}} \mathrm{s}$. From Figure $4 \mathrm{~b}$, significant windows of miscibility can be observed at compositions ranging from slightly less than 100\% PET to 85\% PET (e.g., 0-15\% PEF in PEF-PET mixtures) and 85\% PEF up to slightly less than 100\% PEF (e.g., 85-100 PEF in PET-PEF mixtures). The first derivative of heat flow as a function of temperature, depicted in Figure $4 \mathrm{c}$ can be also quite informative, as it shows dual $T_{\mathrm{g}} \mathrm{s}$ at nearly all compositions. However, the position of the low $T_{\mathrm{g}}$ shifts with composition especially for blends rich in PEF. This can be a signature of partial miscibility [41-43]. Based on those results we conclude that for $10 \%$ PET in the PET/PEF compositions, the blends appear 
to be miscible. Even more importantly, at the other end of the composition range, for PET/PEF compositions of 85/15 it appears that reasonable miscibility exists as well, while the $80 / 20$ blend can be considered partially miscible.
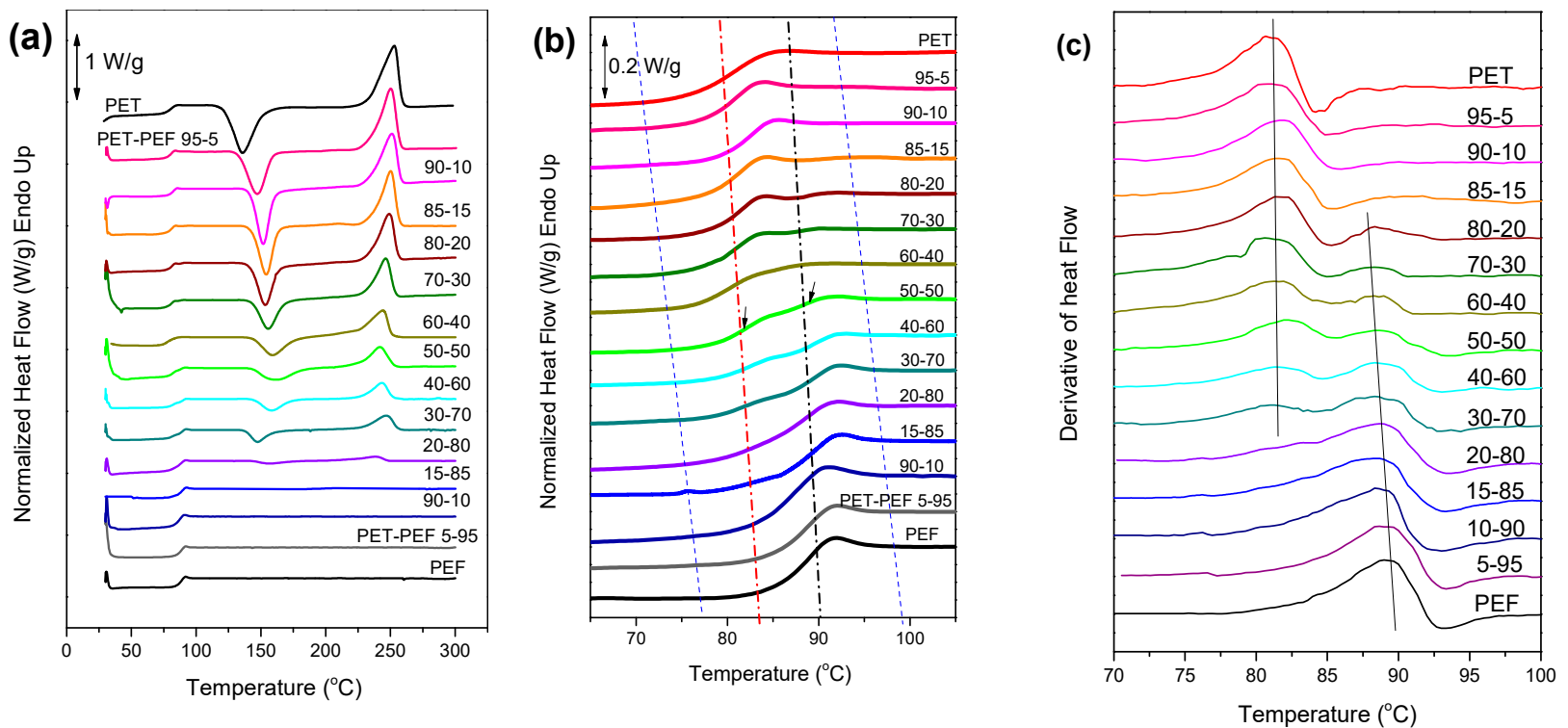

Figure 4. Power compensation DSC thermograms of melt quenched blends at $20{ }^{\circ} \mathrm{C} / \mathrm{min}$ (a) full temperature scale and (b) details of the glass transition temperature range; the black dotted line corresponds to the $T_{\mathrm{g}}$ of PEF and the red dotted line corresponds to the $T_{\mathrm{g}}$ of PET. (c) First derivative of the heat flow plotted as a function of temperature for several PET/PEF compositions. Red and blue arrows indicate glass temperatures of PEF and PET segments, respectively.

Overall, from the above discussion it can be concluded that the window of miscibility can be observed for the PET- and PEF-rich polymer blends where the content of the rich phase is higher than $85 \%$. Additionally, the $80-20$ and $20-80$ blends can be considered partially miscible.

\subsection{Melting Behavior of the Blends}

The melting behavior of the PET-PEF blends with high PET content was studied after isothermal crystallization from the melt at various temperatures. As it can be seen in Figure 5 for the example of the PET-PEF 95- 5 blend, a multiple melting behavior characterized the materials. Similar behaviors have been observed in past for PET and related blends and in general for aromatic polyesters [44-46].

The multiplicity of the melting peaks is related with the isothermal crystallization temperatures. Heating following the crystallization at low temperatures $\left(165^{\circ} \mathrm{C}\right.$ or lower for the PET-PEF 95-5) leads to dual melting peaks. For samples crystallized at temperatures above $170{ }^{\circ} \mathrm{C}$ but below $195^{\circ} \mathrm{C}$, triple melting was evidenced. For crystallization temperatures in the range between 195 and $205^{\circ} \mathrm{C}$, the ultimate temperature melting peak seemed to disappear, but a side peak was also present in place of the peak. Dual melting was observed after crystallization at $T_{c} \mathrm{~S}$ in the range $205^{\circ} \mathrm{C}<T_{c}<227.5^{\circ} \mathrm{C}$. Finally, for $T_{\mathcal{C}}$ s equal or above $230^{\circ} \mathrm{C}$ the two peaks coincided, and a single melting peak was then observed. In all cases of thermograms of Figure 5 the low temperature peak (I) is the well-known annealing peak [47]. 


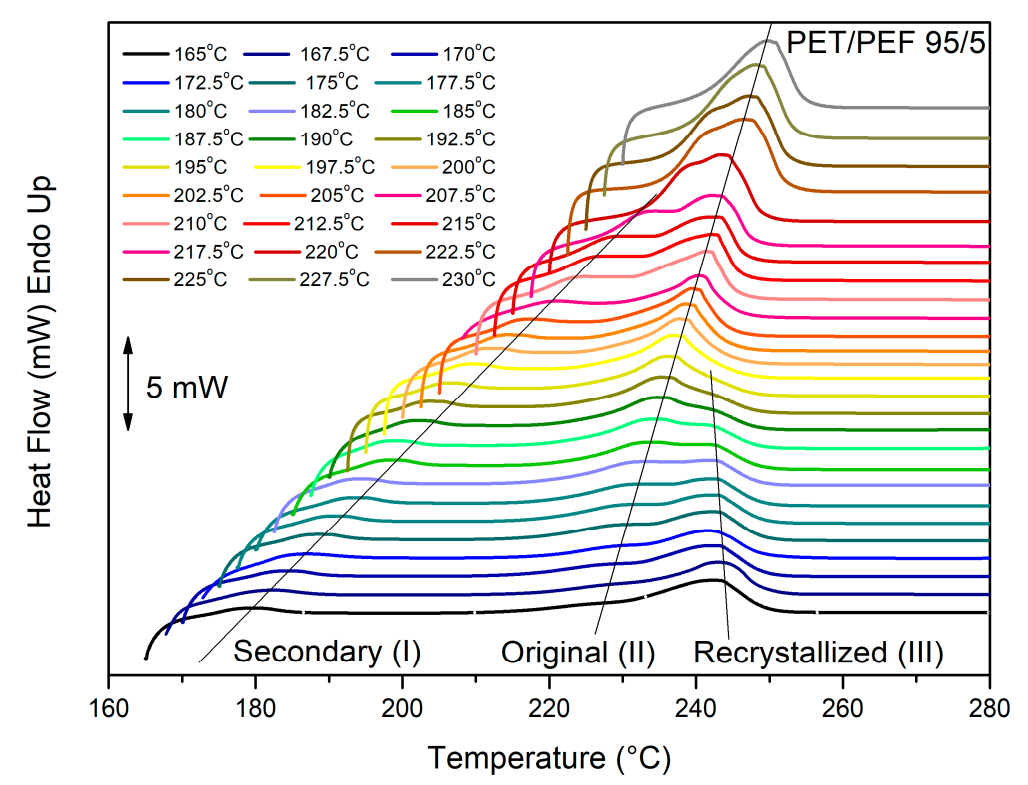

Figure 5. DSC heating scans at $20^{\circ} \mathrm{C} / \mathrm{min}$ for PET-PEF $95-5$ blend samples after crystallization at the indicated temperature.

The middle temperature peak (II) can be attributed to the melting of the original crystals. However, this peak was not always well observed especially upon heating of samples crystallized at very low temperatures, because of the low degree of perfection and reduced thermal stability of the crystals. Finally, the ultimate temperature melting peak (III) was that corresponding to the melting of the reorganized/recrystallized material, that is for crystals stabilized via the crystal perfection processes upon heating.

\subsection{Equilibrium Melting Point}

The most popular method for the estimation of the equilibrium melting point of polymers is that of Hoffmann-Weeks (HF) [48]. According to this procedure, the measured melting temperatures $\left(T_{m}\right)$ of samples isothermally crystallized at various temperatures $\left(T_{c} S\right)$ are plotted against the crystallization temperatures. The linear extrapolation to the line $T_{m}=T_{c}$ gives an intercept equal to $T_{m}^{o}$. The associated equation is:

$$
T_{m}=T_{m}^{o}\left(1-\frac{1}{r}\right)+\frac{T_{c}}{r}
$$

where $T_{m}$ is the observed melting temperature of a crystal formed at a temperature $T_{c}, r$ is the thickening coefficient equal to $l_{c} / l_{g}{ }^{*}$ where $l_{c}$ is the thickness of the grown crystal and $l_{g}{ }^{*}$ is the initial thickness of a chain-folded lamellar crystal [48]. The prerequisite for the application of this theory is the isothermal thickening process of lamellar crystals at a specific crystallization temperature and the dependence of the thickening coefficient on the crystallization temperature.

The values for the temperature of the middle peak (II) were used to construct the Hoffman-Weeks plot for the PET-PEF blends with high PET content. The HW plot for PETPEF 95-05 is shown in Figure 6a. Given the small variations in the melting temperatures of the blends we expect that the equilibrium melting temperature of the blends is in the vicinity of $280^{\circ} \mathrm{C}$. 

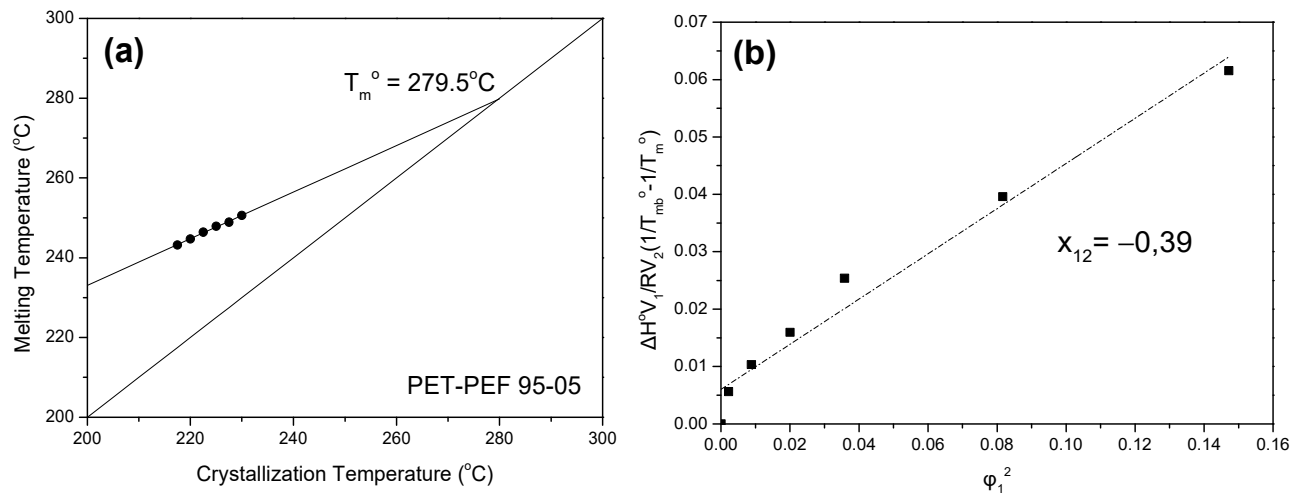

Figure 6. (a) Hoffman-Weeks plot for the determination of the equilibrium meting temperature of PET within the PET-PEF 95-05 blend, (b) Plots of $\frac{\Delta H^{0} V_{1}}{R V_{2}}\left(\frac{1}{T_{m(\text { blend })}^{0}}-\frac{1}{T_{m(\text { pure })}^{0}}\right)$. against $\phi_{1}^{2}$ using equilibrium melting temperatures.

The depression of the melting point of a crystalline polymer blended with an amorphous polymer provides information on the miscibility of the system [49]. In general, melting point depression is associated with morphological effects such as crystal thickness. Additionally, thermodynamic considerations predict that the chemical potential of a polymer will decrease with the addition of a (miscible) diluent. If the polymer is crystallizable, this decrease in chemical potential will result in a decreased equilibrium melting point. The equilibrium melting temperatures can be analyzed by the Flory-Huggins equation [50,51]:

$$
\frac{1}{T_{m \text { (blend })}^{o}}-\frac{1}{T_{m(\text { pure })}^{o}}=\frac{-R}{\Delta H^{0}} \frac{V_{2}}{V_{1}}\left[\frac{\ln \phi_{2}}{m_{2}}+\left(\frac{1}{m_{2}}-\frac{1}{m_{1}}\right) \phi_{1}+\chi_{12} \phi_{1}{ }^{2}\right]
$$

where the subscripts 1 and 2 refer to the amorphous and the crystalline polymer, respectively. $T_{m \text { (pure) }}^{o}$ and $T_{m \text { (blend) }}^{o}$ denote the equilibrium melting points of the pure crystallizable component and that of the blend, respectively. $V$ is the molar volume of the repeating units of the polymers, $R$ is the universal gas constant, $\Delta H^{0}$ is the heat of fusion of the perfectly crystallizable polymer, $m$ is the degree of polymerization, $\phi$ is the volume fraction of the component in the blend, and $\chi_{12}$ is the polymer-polymer interaction parameter. In fact, for the case of PET-PEF blends both polymers are semicrystalline. However, PEF has a lower melting temperature compared to PET $\left(T_{m(\mathrm{PEF})}=215^{\circ} \mathrm{C}\right.$ vs. $\left.T_{m(\mathrm{PET})}=257.5^{\circ} \mathrm{C}\right)$ as can be concluded from the DSC thermograms of Figure 2a. Thus, PEF remains in the liquid molten state at temperatures where PET can easily crystallize $\left(215-230^{\circ} \mathrm{C}\right)$. Based on this, PEF was assumed to be the amorphous component in its blends with PET. The molecular volume of PET is $143.82 \mathrm{~cm}^{3} / \mathrm{mol}$ and $127.27 \mathrm{~cm}^{3} / \mathrm{mol}$ for PEF, while the enthalpy of fusion is $\Delta H_{m}{ }^{0}=26.9 \mathrm{~kJ} / \mathrm{mol}$ for PEF [52].

For high molecular weight polymers, both $m_{1}$ and $m_{2}$ are large and the related terms can be neglected, thus Equation (2) takes the form:

$$
-\frac{\Delta H^{0} V_{1}}{R V_{2}}\left(\frac{1}{T_{m(\text { blend })}^{0}}-\frac{1}{T_{m(\text { pure })}^{0}}\right)=x_{12} \phi_{1}^{2}
$$

If $\chi_{12}$ is assumed to be independent of composition, a plot of the left-hand side of Equation (3) versus $\phi_{1}^{2}$ should give a straight line passing through the origin. The interaction parameter is implicitly referred to a reference volume, $V_{r}$, usually defined in terms of the molar volume of the amorphous component in the mixture. The interaction energy density is another form of expressing the Flory-Huggins interaction parameter, i.e., by eliminating the reference volume [53]:

$$
B=\frac{R T x_{12}}{V_{r}}
$$


Substituting $\phi_{1}^{2}$ from this equation in the Flory-Huggins equation yields the NishiWang equation [54]:

$$
T_{m}^{o}-T_{m b}^{o}=T_{m}^{o} \frac{B V_{2}}{\Delta H_{m}} \phi_{1}^{2}
$$

In an attempt to calculate the polymer-polymer interaction parameter and to eliminate the morphological effect from the melting point depression, the equilibrium melting temperatures for pure PET and PET in the blends of given compositions were used (Figure 6b). The obtained values were $\chi_{12}=-0.39$ and $\mathrm{B}=-3.37 \mathrm{cal} / \mathrm{cm}^{3}$. The negative $\chi_{12}$ and $B$ values are consistent with a miscible system [55]. Additional insight on blend miscibility can be obtained by studying the crystallization kinetics by using both non-isothermal and purely isothermal conditions.

\subsection{Crystallization of the Blends}

\subsubsection{Isothermal Crystallization}

The crystallization of polymer melts is most commonly accompanied by significant heat release. As a result, differential scanning calorimetry is the most accurate technique for the evaluation of the crystallization process. The isothermal crystallization of PET-PEF blends was studied at several crystallization temperatures and the exothermal curves were recorded as a function of time. The relative degree of crystallinity can be obtained if an assumption is made that the evolution of crystallinity is linearly proportional to the evolution of heat released during the crystallization:

$$
X(t)=\frac{\int_{0}^{t}\left(d H_{c} / d t\right) d t}{\int_{0}^{\infty}\left(d H_{c} / d t\right) d t}
$$

where $d H_{c}$ denotes the measured enthalpy of crystallization during an infinitesimal time interval $d t$. The limits $t$ and $\infty$ on the integrals are used to denote the elapsed time during the course of crystallization and at the end of the crystallization process, respectively. The evolution of the relative degree of crystallinity versus time for PET-PEF 95-5 blend can be observed in Figure 7a. The crystallization half-time can be used as a relative measure of the overall crystallization rate. Figure $7 \mathrm{~b}$ shows the variation of the crystallization half-time $\left(t_{1 / 2}\right)$ values with crystallization temperature $\left(T_{c}\right)$. As it can be seen, the crystallization rates decrease with increasing crystallization temperature. In agreement with the results from the non-isothermal crystallization experiments there is a slow demixing process of PET/PEF blends in their melt state as a result of their partial miscibility. In order for PET (or PEF) to crystallize unlike segments will have to diffuse away to create sufficiently large domains for the nucleation and subsequent growth of PET crystals.
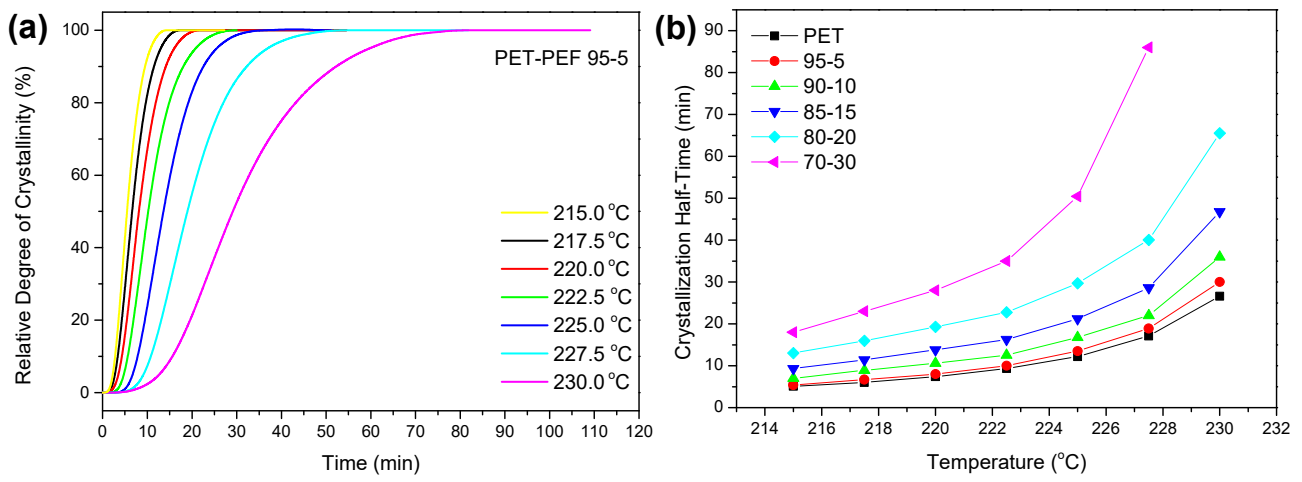

Figure 7. (a) Evolution of the relative degree of crystallinity with time for the PET-PEF 95-5 blend at various temperatures and (b) dependence of the isothermal crystallization half-time on the temperature for blends with high PET content. 


\subsubsection{Application of Secondary Nucleation Theory}

The spherulite growth rate, $G$, as a function of temperature in isothermal crystallization can be described by the Lauritzen-Hoffman secondary nucleation theory [56-58] In this theory, there are two controlling temperatures; the equilibrium melting temperature and the liquid-to-glass temperature. Accordingly, $G$ can be expressed as:

$$
G=G_{0} \exp \left[\frac{-U^{*}}{R\left(T_{\mathcal{c}}-T_{\infty}\right)}\right] \exp \left[\frac{-K_{g}}{T_{\mathcal{c}}(\Delta T) f}\right]
$$

where $G_{0}$ is the pre-exponential factor, the first exponential term contains the contribution of diffusion process to the growth rate, while the second exponential term is the contribution of the nucleation process; $U^{*}$ denotes the activation energy which characterizes molecular diffusion across the interfacial boundary between the melt and the crystal front, and $T_{\infty}$ is the "ideal" glass temperature located below the conventional $T_{\mathrm{g}}$. In a recent dielectric spectroscopy study the first term was extracted from the segmental dynamics of amorphous PEF with parameters, $U^{*}=4.57 \mathrm{kcal} / \mathrm{mol}$ and $T_{\infty}=289 \mathrm{~K} . K_{g}$ is a nucleation constant and $\Delta T$ denotes the degree of undercooling $\left(\Delta T=T_{m}{ }^{0}-T_{\mathrm{c}}\right) ; f$ is a correction factor which is close to unity at high temperatures and is given as $f=2 T_{c} /\left(T_{m}{ }^{0}+T_{c}\right)$ [57]. Equation (7) can be also written in its logarithmic form and growth rate $G$, which should be obtained essentially by the spherulite growth, was calculated by the inverse of crystallization half time $\left(1 / t_{1 / 2}\right)$. Actually, this substitution has been widely used in crystallization studies of polymers [57]. Then, plotting $\log G+\frac{U^{*}}{2.30 R\left(T_{c}-T_{\infty}\right)}$ with respect to $1 /\left(T_{\mathcal{C}}(\Delta T) f\right)$ a straight line should appear, for each crystallization regime, having a slope equal to $K_{g}$. Figure 8 gives the plot for the PET-PEF blends. From the slope and the intercept of the corresponding line, the nucleation parameter, $K_{g}$ and $\ln G_{0}$ can be obtained for each regime. The calculated values for $K_{g I I}$ are summarized in Table 1.

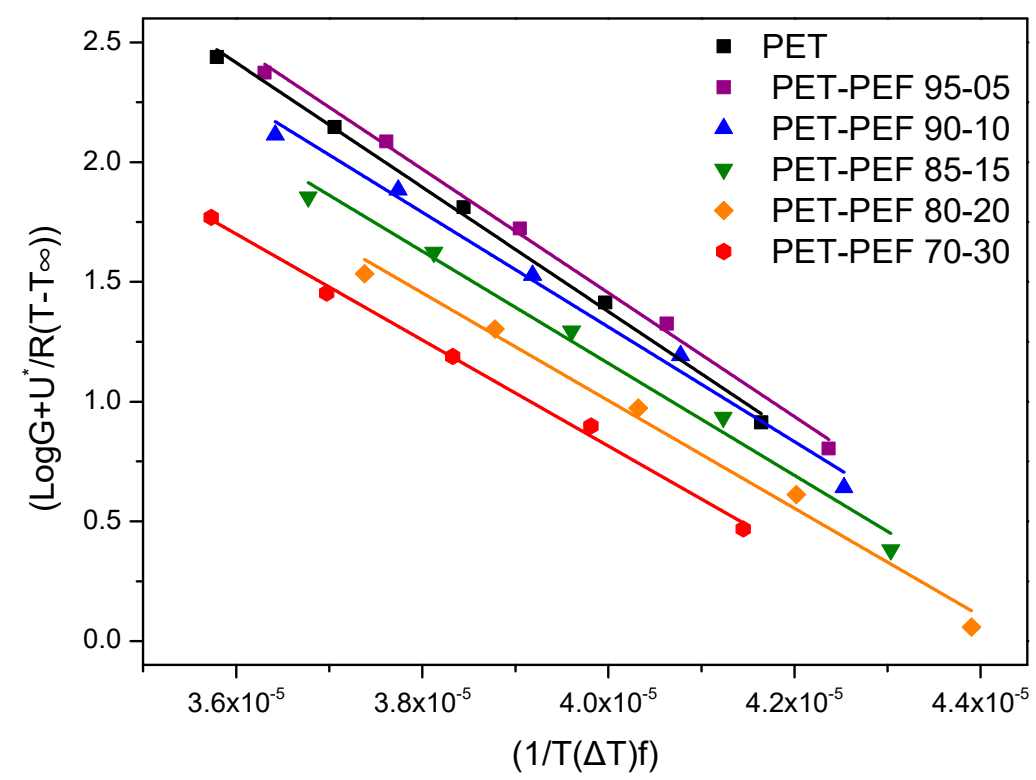

Figure 8. Lauritzen Hoffman-plots for PET and the blends. 
Table 1. Results from the Lauritzen-Hoffman analysis on the crystallizable blends.

\begin{tabular}{|c|c|c|c|c|c|}
\hline Blend & $\begin{array}{c}\mathrm{K}_{\mathrm{gII}} \times 10^{-5} \\
\left(\mathrm{~K}^{2}\right)\end{array}$ & $\begin{array}{c}\sigma \sigma_{e} \times 10^{4} \\
\left(\mathrm{~J}^{2} / \mathrm{m}^{4}\right)\end{array}$ & $\begin{array}{c}\sigma \times 10^{2} \\
\left(\mathrm{~J} / \mathrm{m}^{2}\right)\end{array}$ & $\begin{array}{c}\sigma_{e} \times 10^{2} \\
\left(\mathrm{~J} / \mathrm{m}^{2}\right)\end{array}$ & $q(\mathrm{~kJ} / \mathrm{mol})$ \\
\hline PET & 2.60 & 11.9 & 1.09 & 10.9 & 35.7 \\
\hline PET-PEF 95-05 & 2.58 & 11.8 & 1.09 & 10.8 & 35.4 \\
\hline PET-PEF 90-10 & 2.40 & 11.0 & 1.09 & 10.1 & 33.1 \\
\hline PET-PEF 85-15 & 2.34 & 10.7 & 1.09 & 9.85 & 32.3 \\
\hline PET-PEF 80-20 & 2.25 & 10.3 & 1.09 & 9.47 & 31.0 \\
\hline PET-PEF 70-30 & 2.21 & 10.2 & 1.09 & 9.37 & 30.7 \\
\hline
\end{tabular}

For a secondary or heterogeneous nucleation, $K_{g}$ can be calculated from [57]:

$$
K_{g}=\frac{n \sigma \sigma_{e} b_{0} T_{m}^{0}}{\Delta h_{f} \rho_{c} k_{B}}
$$

where, $n$ is a constant equal to 4 for regime I and III and 2 for regime II, $\sigma$, and $\sigma_{e}$ are the side surface (lateral) and fold surface (end) free energies which measure the work required to create a new surface, $b_{0}$ is the single layer thickness ( $0.595 \mathrm{~nm}$ for PET), $\Delta h_{f} \rho_{c}=\Delta H_{f}$ is the enthalpy of melting per unit volume and was assumed to be $\Delta H=2.04 \times 10^{8} \mathrm{~J} / \mathrm{m}^{3}$ for PET (given that the heat of fusion is $26.9 \mathrm{~kJ} / \mathrm{mol}$ the density of the crystalline PET is $\left.1.445 \mathrm{~g} / \mathrm{cm}^{3}\right)$ and $k_{B}$ is the Boltzmann constant $\left(k_{B}=1.38 \times 10^{-23} \mathrm{~J} / \mathrm{K}\right)$. Below 236 and above $167^{\circ} \mathrm{C}$ a crystallization regime II is assumed [59]. The resulting value for the product $\sigma \sigma_{e}$ using $K_{g \mathrm{II}}=2.6 \times 10^{5} \mathrm{~K}^{2}$ was $\sigma \sigma_{e}=11.9 \times 10^{-4} \mathrm{~J}^{2} / \mathrm{m}^{4}$. The results for the blends are summarized in Table 1. The lateral surface free energy, $\sigma$ is commonly estimated as Equation (9):

$$
\sigma=\alpha\left(\Delta h_{f}\right)\left(a_{0} b_{0}\right)^{0.5}
$$

where, $\alpha$ was derived empirically to be 0.11 by analogy with the well-known behaviour of hydrocarbons. $a_{0}$ and $b_{0}$ factors are the monomolecular width and layer thickness, respectively. For PET $a_{0}=0.457 \mathrm{~nm}$ and $b_{0}=0.595 \mathrm{~nm}$. Accordingly, $\sigma=1.09 \times 10^{-2} \mathrm{~J} / \mathrm{m}^{2}$. So, for PET $\sigma_{e}=10.9 \times 10^{-2} \mathrm{~J} / \mathrm{m}^{2}$, a value that is close to previously reported ones $[60,61]$.

Finally, the work of chain folding, $q$, which is most closely correlated with molecular structure, can be calculated from [62]:

$$
q=2 a_{0} b_{0} \sigma_{e}
$$

For PET it was found that $q=35.7 \mathrm{~kJ} / \mathrm{mol}$. The values for the blends were slightly lower indicating that the folding of macromolecular chains takes place easier in these samples, therefore facilitating the growth of crystals (Table 1).

\subsubsection{Non-Isothermal Crystallization}

The non-isothermal crystallization of PET was investigated under several cooling rates, ranging from 1.25 to $10^{\circ} \mathrm{C} / \mathrm{min}$ (Figure 9a). The higher the cooling rate is, the broader the crystallization peaks. Furthermore, the increase of cooling rate leads to reduced peak temperatures, since the crystallization phenomenon starts and ends at higher times. From the data of the crystallization exotherms as a function of temperature $d H_{c} / d T$, the relative crystallinity as a function of temperature can be calculated as follows [63-65]:

$$
X(T)=\frac{\int_{T_{0}}^{T_{\mathcal{c}}}\left(d H_{\mathcal{c}} / d T\right) d T}{\int_{T_{0}}^{T_{\infty}}\left(d H_{\mathcal{c}} / d T\right) d T}
$$


where $T_{0}$ denotes the initial crystallization temperature and $T_{c}$ and $T_{\infty}$ the crystallization temperatures at time $t$ and after the competition of the crystallization process, respectively. Additionally, once $X(T)$ is obtained, the evolution of the relative degree of crystallinity can be plotted as a function of time, by using the time-temperature transformation: $t=$ $\left(T_{0}-T\right) / a[63,66]$. The DSC curves from the non-isothermal crystallization at $10^{\circ} \mathrm{C} / \mathrm{min}$ for all blends are presented in Figure 9b. PET and the samples up to $30 \mathrm{wt} . \%$ PEF display the characteristic exothermic peaks, indicating the crystallization, while for PEF content higher than $30 \mathrm{wt} . \%$, there is no clear crystallization. Finally, from the results of the peak temperature versus cooling rate for the crystallizable blends (Figure 9c), it can be seen that the characteristic peak crystallization temperatures decrease with increasing PEF content, independent of the cooling rate. This finding suggests that the demixing process of PET/PEF blends in their melt state is very slow and limited as a result of their partial miscibility.
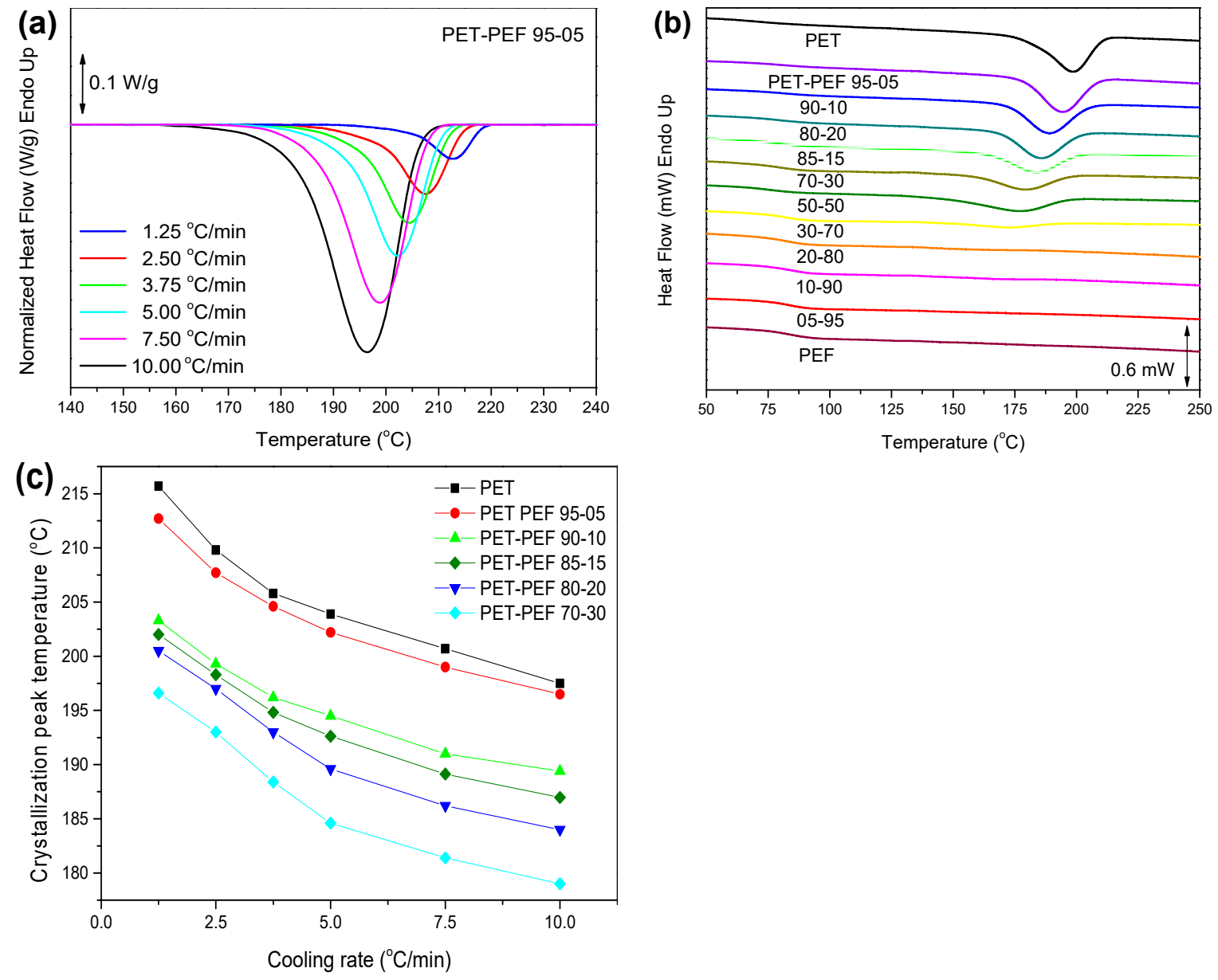

Figure 9. (a) DSC traces of non-isothermal crystallization of PET-PEF 95-05 at various cooling rates, (b) DSC traces of the non-isothermal crystallization of all blends under cooling at $10^{\circ} \mathrm{C} / \mathrm{min}$, (c) peak crystallization temperatures versus cooling rate for the blends that were crystallized.

\subsection{Reactive Blending}

The use of random copolymers as compatibilizers has been established as an effective strategy to enhance miscibility in an otherwise immiscible (or partially miscible) blend. However, the formulation and preparation of a tailored random copolymer is a timeconsuming process where precise steps need to be followed. For this reason, reactive blending is another process that can be followed for the preparation of miscible blends [67]. When two polyesters are mixed at temperatures above the melting point of at least one 
of them, transesterification reactions take place, which lead to the formation of block copolymers if the duration of mixing is long enough. In this work, we applied reactive blending for the PEF-PET $60-40$ blends at $280^{\circ} \mathrm{C}$. The DSC curves of the blend at different reactive blending times can be seen in Figure 10a, while the glass transition region of interest can be seen in Figure 10b. Since a block copolymer is formed at increasing blending times, there is a suppression of cold-crystallization and a decrease of the melting temperatures. It is obvious that after $7.5 \mathrm{~min}$ of reactive blending the double glass transition of the blend is transformed to a single one, suggesting the formation of a block copolymer that is composed of dynamically homogeneous and thermodynamically miscible segments.
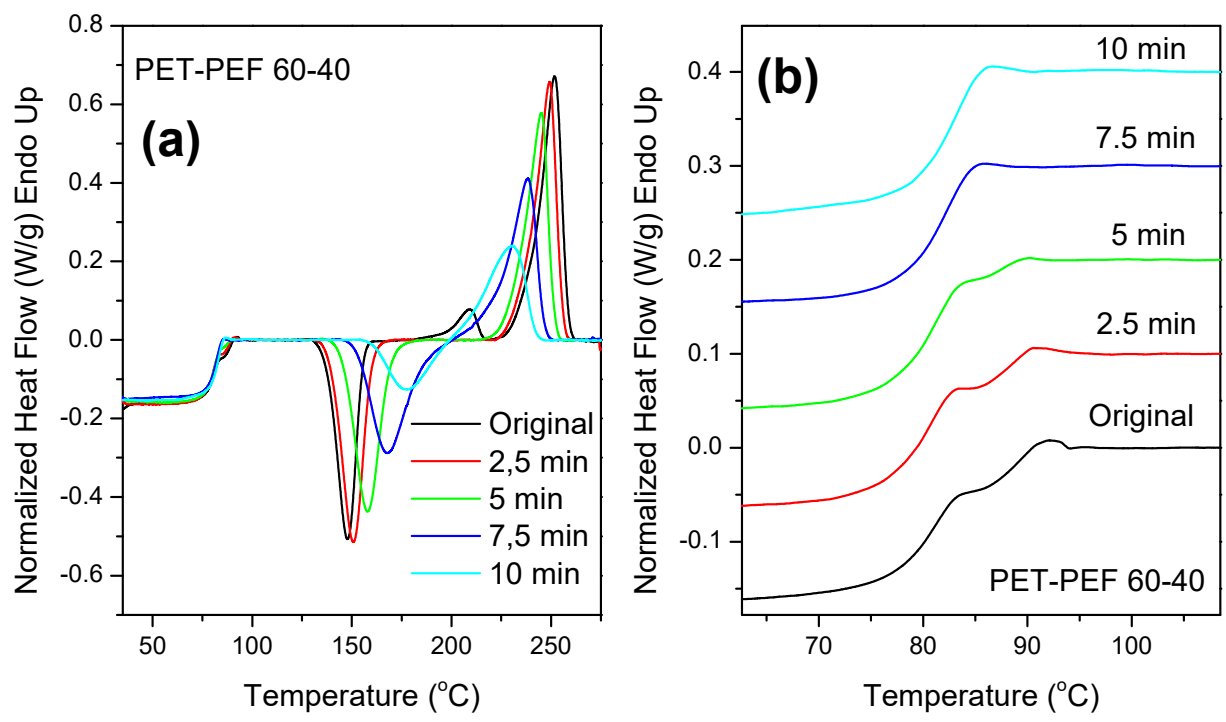

Figure 10. (a) Effect of blending time on the DSC curves of a PET-PEF 60-40 copolymer, (b) zoom-in of the glass transition temperature region of the blend at different blending times.

\subsection{Morphological Study of the Blends}

The blend morphology was studied by means of polarized light microscopy under isothermal crystallization conditions at $210^{\circ} \mathrm{C}$. PET and PEF are two polyesters showing quite different morphologies upon isothermal crystallization. As can be seen in Figure 11a, PET crystallizes fast and, in any case, much faster than PEF. This might be the main limiting factor for miscibility in their blends. In the images presented in Figure 11 one can mainly see PET spherulites. This is because at $210{ }^{\circ} \mathrm{C}$ PEF crystallizes very slowly, so in the timescale of the experiments no PEF spherulites are expected to form. Moreover, in contrast to Figure 11a, the nucleation density of PET in the blends was reduced, so that well distinguishable spherulites formed, of significant diameter. Furthermore, the growth rates were reduced with increasing PEF content in the mixtures. 

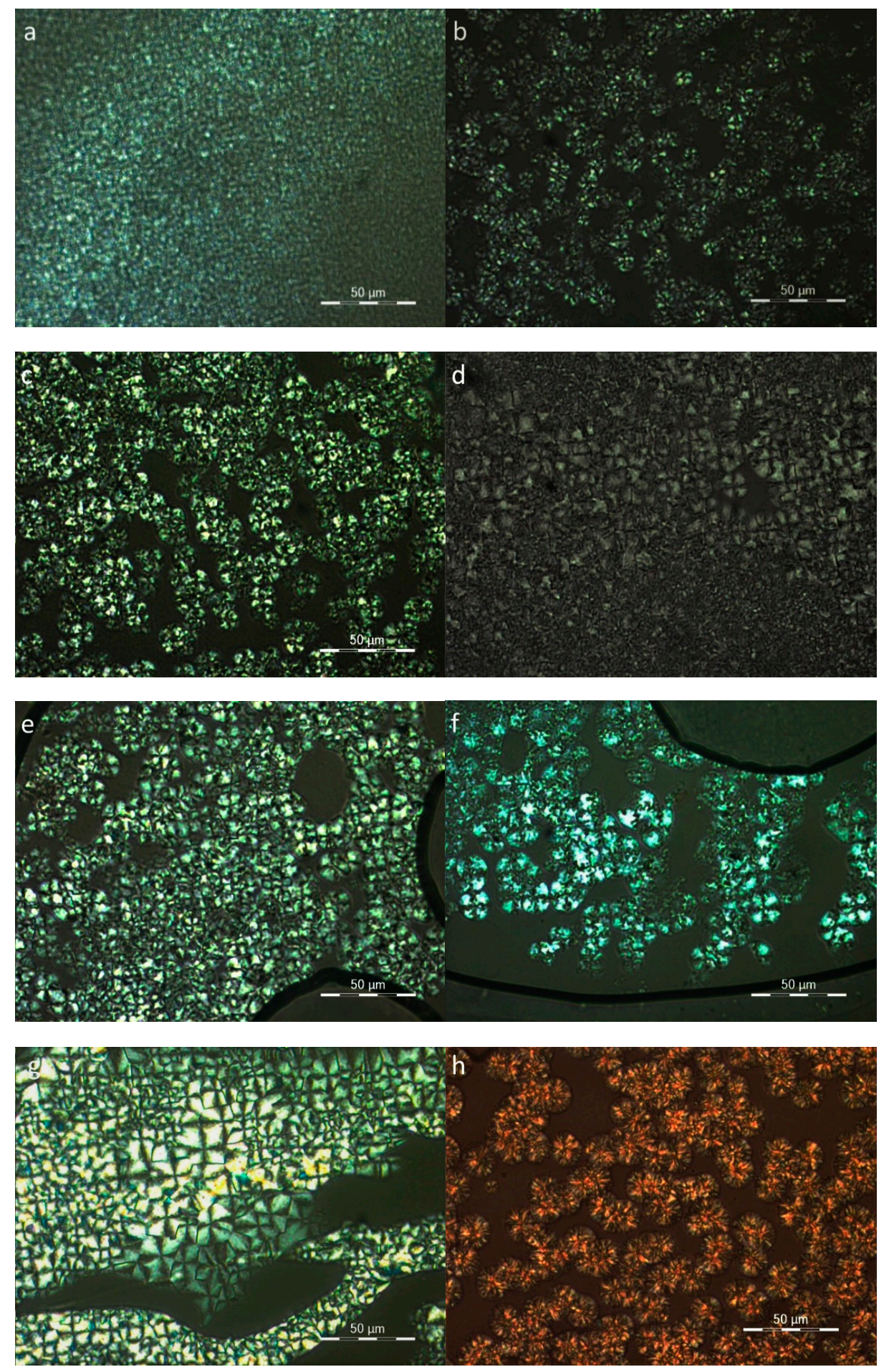

Figure 11. PLM photos recorded at $210^{\circ} \mathrm{C}$ for the blends: (a) neat PET, (b) PET-PEF 90-10, (c) PET-PEF 80-20, (d) PET-PEF 60-40, (e) PET-PEF 50-50, (f) PET-PEF 40-60, (g) PET-PEF 30-70, (h) neat PEF.

\section{Conclusions}

Poly(ethylene terephthalate)/poly(ethylene 2,5-furandicarboxylate) blends have been successfully prepared by solution blending. The thermal transition temperatures and the thermodynamics of miscibility phenomena have been studied in detail by the use of advanced calorimetric techniques and measurement strategies. Miscibility was initially achieved at PET-rich (higher than 85\%) and low-PET (lower than 15\%) blends, while at intermediate compositions the blends were partially miscible. This conclusion has been 
exported from the study of both the glass transition temperatures of the blends and the Flory-Huggins interaction parameter. The equilibrium melting temperature of the PET within the PET-PEF 95-5 blend was obtained from the Hoffman-Weeks method and was found to be in the vicinity of $280^{\circ} \mathrm{C}$. Additionally, from the non-isothermal crystallization study, it was found that slow demixing process of PET/PEF blends takes place in their melt state as a result of their partial miscibility. Finally, reactive blending was also applied to enhance miscibility; after 7.5 min of mixing, the polymer blend was eventually transformed into a copolymer as concluded from the transformation of the dual glass transition to a single glass transition temperature.

The produced blends can be considered as excellent candidates to replace products and applications where PET is dominating the market against other biobased plastics. The presence of eco-friendly PEF, originating from renewable resources in the blends, enables a reduction of the environmental impact from the production of fully-PET based products while at the same time, the recyclability of the ultimate products remains high. Such blends are expected to play a major role in the near future for the increase in sustainability and the transition to green economies.

Author Contributions: Conceptualization, D.G.P. and G.Z.P.; Data curation, R.O.I., G.N.N., S.E. and G.Z.P.; Formal analysis, D.G.P., I.T., R.O.I., G.N.N., S.E. and G.Z.P.; Investigation, I.T., R.O.I., G.N.N. and N.K.; Methodology, D.G.P., I.T., N.K., D.S.A. and G.Z.P.; Project administration, D.S.A. and G.Z.P.; Resources, D.N.B. and G.Z.P.; Supervision, D.N.B., D.S.A. and G.Z.P.; Validation, S.E. and G.Z.P.; Visualization, D.N.B.; Writing—original draft, D.G.P. and G.Z.P.; Writing—review \& editing, D.G.P., D.N.B. and G.Z.P. All authors have read and agreed to the published version of the manuscript.

Funding: This research received no external funding.

Institutional Review Board Statement: Not applicable.

Informed Consent Statement: Not applicable.

Data Availability Statement: The data presented in this study are available on reasonable request from the corresponding author.

Acknowledgments: This publication is based upon work from COST Action FUR4Sustain, CA18220, supported by COST (European Cooperation in Science and Technology).

Conflicts of Interest: The authors declare no conflict of interest.

\section{References}

1. Sanders, J.P.M.; Clark, J.H.; Harmsen, G.J.; Heeres, H.J.; Heijnen, J.J.; Kersten, S.R.A.; Swaaij, W.P.M.; Moulijin, J.A. Process intensification in the future production of base chemicals from biomass. Chem. Eng. Process. 2012, 51, 117-136. [CrossRef]

2. Zhang, L.; Jiang, Y.; Xiong, Z.; Liu, X.; Na, H.; Zhang, R.; Zhu, J. Highly recoverable rosin-based shape memory polyurethanes. J. Mater. Chem. A 2013, 1, 3263-3267. [CrossRef]

3. Storz, H.; Vorlop, K.D. Bio-based plastics: Status, challenges and trends. Appl. Agric. For. Res. 2013, 63, 321-332.

4. Mülhaupt, R. Green Polymer Chemistry and Bio-based Plastics: Dreams and Reality. Macromol. Chem. Phys. 2012, $214,159-174$. [CrossRef]

5. Schneiderman, D.K.; Hillmyer, M.A. 50th Anniversary Perspective: There Is a Great Future in Sustainable Polymers. Macromolecules 2017, 50, 3733-3749. [CrossRef]

6. Gandini, A.; Lacerda, T.M.; Carvalho, A.J.F.; Trovatti, E. Progress of Polymers from Renewable Resources: Furans, Vegetable Oils, and Polysaccharides. Chem. Rev. 2016, 116, 1637-1669. [CrossRef] [PubMed]

7. Lu, J.; Wu, L.; Li, B.-G. High Molecular Weight Polyesters Derived from Biobased 1,5-Pentanediol and a Variety of Aliphatic Diacids: Synthesis, Characterization, and Thermo-Mechanical Properties. ACS Sustain. Chem. Eng. 2017, 5, 6159-6166. [CrossRef]

8. Sousa, A.F.; Vilela, C.; Fonseca, A.C.; Matos, M.; Freire, C.S.R.; Gruter, G.-J.M.; Coelho, J.F.J.; Silvestre, A.J.D. Biobased polyesters and other polymers from 2,5-furandicarboxylic acid: A tribute to furan excellency. Polym. Chem. 2015, 6, 5961-5983. [CrossRef]

9. Morales-Huerta, J.C.; Ciulik, C.B.; De Ilarduya, A.M.; Muñoz-Guerra, S. Fully bio-based aromatic-aliphatic copolyesters: Poly(butylene furandicarboxylate-co-succinate)s obtained by ring opening polymerization. Polym. Chem. 2017, 8, 748-760. [CrossRef]

10. Papageorgiou, G.Z.; Tsanaktsis, V.; Papageorgiou, D.G.; Exarhopoulos, S.; Papageorgiou, M.; Bikiaris, D.N. Evaluation of polyesters from renewable resources as alternatives to the current fossil-based polymers. Phase transitions of poly(butylene 2,5-furan-dicarboxylate). Polymer 2014, 55, 3846-3858. [CrossRef] 
11. Papageorgiou, G.Z.; Tsanaktsis, V.; Papageorgiou, D.G.; Chrissafis, K.; Exarhopoulos, S.; Bikiaris, D.N. Furan-based polyesters from renewable resources: Crystallization and thermal degradation behavior of poly(hexamethylene 2,5-furan-dicarboxylate). Eur. Polym. J. 2015, 67, 383-396. [CrossRef]

12. Zhang, Z.; Deng, K. Recent Advances in the Catalytic Synthesis of 2,5-Furandicarboxylic Acid and Its Derivatives. ACS Catal. 2015, 5, 6529-6544. [CrossRef]

13. Rosenboom, J.-G.; Hohl, D.K.; Fleckenstein, P.; Storti, G.; Morbidelli, M. Bottle-grade polyethylene furanoate from ring-opening polymerisation of cyclic oligomers. Nat. Commun. 2018, 9, 1-7. [CrossRef] [PubMed]

14. Burgess, S.K.; Wenz, G.B.; Kriegel, R.M.; Koros, W.J. Penetrant transport in semicrystalline poly(ethylene furanoate). Polymer 2016, 98, 305-310. [CrossRef]

15. Burgess, S.K.; Leisen, J.E.; Kraftschik, B.E.; Mubarak, C.R.; Kriegel, R.M.; Koros, W.J. Chain Mobility, Thermal, and Mechanical Properties of Poly(ethylene furanoate) Compared to Poly(ethylene terephthalate). Macromolecules 2014, 47, 1383-1391. [CrossRef]

16. Van Berkel, J.G.; Guigo, N.; Kolstad, J.J.; Sipos, L.; Wang, B.; Dam, M.A.; Sbirrazzuoli, N. Isothermal Crystallization Kinetics of Poly (Ethylene 2,5-Furandicarboxylate). Macromol. Mater. Eng. 2015, 300, 466-474. [CrossRef]

17. Dimitriadis, T.; Bikiaris, D.N.; Papageorgiou, G.Z.; Floudas, G. Molecular Dynamics of Poly(ethylene-2,5-furanoate) (PEF) as a Function of the Degree of Crystallinity by Dielectric Spectroscopy and Calorimetry. Macromol. Chem. Phys. 2016, 217, $2056-2062$. [CrossRef]

18. Papageorgiou, G.Z.; Papageorgiou, D.G.; Terzopoulou, Z.; Bikiaris, D.N. Production of bio-based 2,5-furan dicarboxylate polyesters: Recent progress and critical aspects in their synthesis and thermal properties. Eur. Polym. J. 2016, 83, 202-229. [CrossRef]

19. Tomisawa, R.; Ikaga, T.; Kim, K.; Ohkoshi, Y.; Okada, K.; Masunaga, H.; Kanaya, T.; Masuda, M.; Maeda, Y. Effect of draw ratio on fiber structure development of polyethylene terephthalate. Polymer 2017, 116, 357-366. [CrossRef]

20. Van Uytvanck, P.; Haire, G.; Marshall, P.; Dennis, J. Impact on the Polyester Value Chain of Using p-Xylene Derived from Biomass. ACS Sustain. Chem. Eng. 2017, 5, 4119-4126. [CrossRef]

21. Galbis, J.A.; García-Martín, M.D.G.; De Paz, M.V.; Galbis, E. Synthetic Polymers from Sugar-Based Monomers. Chem. Rev. 2016, 116, 1600-1636. [CrossRef] [PubMed]

22. Muñoz-Guerra, S.; Lavilla, C.; Japu, C.; De Ilarduya, A.M. Renewable terephthalate polyesters from carbohydrate-based bicyclic monomers. Green Chem. 2014, 16, 1716-1739. [CrossRef]

23. Kim, G.S.; Son, J.M.; Lee, J.K.; Lee, K.H. Morphology development and crystallization behavior of poly(ethylene terephthalate)/poly(trimethylene terephthalate) blends. Eur. Polym. J. 2010, 46, 1696-1704. [CrossRef]

24. Aoyama, S.; Park, Y.T.; Ougizawa, T.; Macosko, C.W. Melt crystallization of poly(ethylene terephthalate): Comparing addition of graphene vs. carbon nanotubes. Polymer 2014, 55, 2077-2085. [CrossRef]

25. Docampo, P.; Ball, J.M.; Darwich, M.; Eperon, G.E.; Snaith, H.J. Efficient organometal trihalide perovskite planar-heterojunction solar cells on flexible polymer substrates. Nat. Commun. 2013, 4, 2761. [CrossRef] [PubMed]

26. Kawai, F.; Kawabata, T.; Oda, M. Current State and Perspectives Related to the Polyethylene Terephthalate Hydrolases Available for Biorecycling. ACS Sustain. Chem. Eng. 2020, 8, 8894-8908. [CrossRef]

27. Kim, H.J.; Peng, X.; Shin, Y.; Hillmyer, M.A.; Ellison, C.J. Blend Miscibility of Poly(ethylene terephthalate) and Aromatic Polyesters from Salicylic Acid. J. Phys. Chem. B 2021, 125, 450-460. [CrossRef]

28. Bai, H.; Xiu, H.; Gao, J.; Deng, H.; Zhang, Q.; Yang, M.; Fu, Q. Tailoring impact toughness of poly (L-lactide)/poly ( $\varepsilon-$ caprolactone)(PLLA/PCL) blends by controlling crystallization of PLLA matrix. ACS Appl. Mater. Interfaces 2012, 4, 897-905. [CrossRef]

29. Doroshenko, M.; Gonzales, M.; Best, A.; Butt, H.-J.; Koynov, K.; Floudas, G. Monitoring the Dynamics of Phase Separation in a Polymer Blend by Confocal Imaging and Fluorescence Correlation Spectroscopy. Macromol. Rapid Commun. 2012, 33, 1568-1573. [CrossRef]

30. Blochowiak, M.; Pakula, T.; Butt, H.-J.; Floudas, G. Miscibility of binary blends of ethylene/norbornene copolymers: Comparison to a lattice cluster theory. Polymer 2007, 48, 6010-6017. [CrossRef]

31. Suzuki, T.; Tanaka, H.; Nishi, T. Miscibility and transesterification in bisphenol A polycarbonate/poly(ethylene terephthalate) blends. Polymer 1989, 30, 1287-1297. [CrossRef]

32. Daubeny, R.D.P.; Bunn, C. The crystal structure of polyethylene terephthalate. Proc. Royal 1954, 226, 531-542.

33. Mao, Y.; Kriegel, R.M.; Bucknall, D.G. The crystal structure of poly(ethylene furanoate). Polymer 2016, 102, 308-314. [CrossRef]

34. Tsanaktsis, V.; Papageorgiou, D.G.; Exarhopoulos, S.; Bikiaris, D.N.; Papageorgiou, G.Z. Crystallization and Polymorphism of Poly(ethylene furanoate). Cryst. Growth Des. 2015, 15, 5505-5512. [CrossRef]

35. Lotti, N.; Munari, A.; Gigli, M.; Gazzano, M.; Tsanaktsis, V.; Bikiaris, D.N.; Papageorgiou, G.Z. Thermal and structural response of in situ prepared biobased poly(ethylene 2,5-furan dicarboxylate) nanocomposites. Polymer 2016, 103, 288-298. [CrossRef]

36. Papageorgiou, G.Z.; Papageorgiou, D.G.; Chrissafis, K.; Bikiaris, D.; Will, J.; Hoppe, A.; Roether, J.A.; Boccaccini, A.R. Crystallization and Melting Behavior of Poly(Butylene Succinate) Nanocomposites Containing Silica-Nanotubes and Strontium Hydroxyapatite Nanorods. Ind. Eng. Chem. Res. 2013, 53, 678-692. [CrossRef]

37. Stoclet, G.; du Sart, G.G.; Yeniad, B.; de Vos, S.; Lefebvre, J. Isothermal crystallization and structural characterization of poly(ethylene-2,5-furanoate). Polymer 2015, 72, 165-176. [CrossRef] 
38. Martino, L.; Guigo, N.; Van Berkel, J.G.; Sbirrazzuoli, N. Influence of organically modified montmorillonite and sepiolite clays on the physical properties of bio-based poly(ethylene 2,5-furandicarboxylate). Compos. Part B Eng. 2017, 110, 96-105. [CrossRef]

39. Xie, H.; Meng, H.; Wu, L.; Li, B.G.; Dubois, P. In-situ synthesis, thermal and mechanical properties of biobased poly (ethylene 2, 5-furandicarboxylate)/montmorillonite (PEF/MMT) nanocomposites. Eur. Polym. J. 2019, 121, 109266. [CrossRef]

40. Woo, E.M.; Kuo, Y.-H. Complete miscibility of ternary aryl polyesters demonstrating a new criterion and horizon for miscibility characterization. J. Polym. Sci. Part B Polym. Phys. 2003, 41, 2394-2404. [CrossRef]

41. Lodge, T.P.; McLeish, T.C.B. Self-Concentrations and Effective Glass Transition Temperatures in Polymer Blends. Macromolecules 2000, 33, 5278-5284. [CrossRef]

42. Lodge, T.P.; Wood, E.R.; Haley, J.C. Two calorimetric glass transitions do not necessarily indicate immiscibility: The case of PEO/PMMA. J. Polym. Sci. Part B Polym. Phys. 2006, 44, 756-763. [CrossRef]

43. Kordjazi, Z.; Ajji, A. Partially miscible polymer blends of ethyl cellulose and hydroxyl terminated polybutadiene. Polymer 2020, 211, 123067. [CrossRef]

44. Papageorgiou, G.Z.; Tsanaktsis, V.; Bikiaris, D.N. Synthesis of poly(ethylene furandicarboxylate) polyester using monomers derived from renewable resources: Thermal behavior comparison with PET and PEN. Phys. Chem. Chem. Phys. 2014, 16, 7946-7958. [CrossRef] [PubMed]

45. Chen, M.-J.; Shi, Q.-S. Transforming Sugarcane Bagasse into Bioplastics via Homogeneous Modification with Phthalic Anhydride in Ionic Liquid. ACS Sustain. Chem. Eng. 2015, 3, 2510-2515. [CrossRef]

46. Minakov, A.A.; Mordvintsev, D.A.; Schick, C. Melting and reorganization of poly(ethylene terephthalate) on fast heating (1000 K/s). Polymer 2004, 45, 3755-3763. [CrossRef]

47. Zhou, C.; Clough, S.B. Multiple melting endotherms of poly(ethylene terephthalate). Polym. Eng. Sci. 1988, 28, 65-68. [CrossRef]

48. Hoffman, J.D.; Weeks, J.J. Melting process and the equilibrium melting temperature of polychlorotrifluoroethylene. J. Res. Natl. Bur. Stand. Sect. A Phys. Chem. 1962, 66A, 13. [CrossRef]

49. Runt, J.; Miley, D.M.; Zhang, X.; Gallagher, K.P.; McFeaters, K.; Fishburn, J. Crystallization of poly(butylene terephthalate) and its blends with polyarylate. Macromolecules 1992, 25, 1929-1934. [CrossRef]

50. Flory, P.J. Thermodynamics of Crystallization in High Polymers. IV. A Theory of Crystalline States and Fusion in Polymers, Copolymers, and Their Mixtures with Diluents. J. Chem. Phys. 1949, 17, 223-240. [CrossRef]

51. Flory, P.J. Theory of crystallization in copolymers. Trans. Faraday Soc. 1955, 51, 848-857. [CrossRef]

52. Konstantopoulou, M.; Terzopoulou, Z.; Nerantzaki, M.; Tsagkalias, J.; Achilias, D.S.; Bikiaris, D.N.; Exarhopoulos, S.; Papageorgiou, D.G.; Papageorgiou, G.Z. Poly(ethylene furanoate-co-ethylene terephthalate) biobased copolymers: Synthesis, thermal properties and cocrystallization behavior. Eur. Polym. J. 2017, 89, 349-366. [CrossRef]

53. Meaurio, E.; Sanchez-Rexach, E.; Hernandez, E.Z.; Lejardi, A.; Sanchez-Camargo, A.D.P.; Sarasua, J.-R. Predicting miscibility in polymer blends using the Bagley plot: Blends with poly(ethylene oxide). Polymer 2017, 113, 295-309. [CrossRef]

54. Qiu, Z.; Komura, M.; Ikehara, T.; Nishi, T. Poly (butylene succinate)/poly (vinyl phenol) blends. Part 1. Miscibility and crystallization. Polymer 2003, 44, 8111-8117. [CrossRef]

55. Penning, J.P.; Manley, R.S.J. Miscible Blends of Two Crystalline Polymers. 1. Phase Behavior and Miscibility in Blends of Poly(vinylidene fluoride) and Poly(1,4-butylene adipate). Macromolecules 1996, 29, 77-83. [CrossRef]

56. Lauritzen, J.I., Jr.; Hoffman, J.D. Formation of polymer crystals with folded chains from dilute solution. J. Chem. Phys. 1959, 31, 1680-1681. [CrossRef]

57. Hoffman, J.D.; Miller, R.L. Kinetic of crystallization from the melt and chain folding in polyethylene fractions revisited: Theory and experiment. Polymer 1997, 38, 3151-3212. [CrossRef]

58. Medellín-Rodríguez, F.J.; Phillips, P.J.; Lin, J.S. Application of Secondary Nucleation Theory to Semirigid Macromolecules: PEEK, PET, and PEN. Macromolecules 1995, 28, 7744-7755. [CrossRef]

59. Rahman, M.; Nandi, A.K. On the crystallization mechanism of poly(ethylene terepthalate) in its blends with poly(vinylidene fluoride). Polymer 2002, 43, 6863-6870. [CrossRef]

60. Lu, X.; Hay, J. Isothermal crystallization kinetics and melting behaviour of poly(ethylene terephthalate). Polymer 2001, 42, 9423-9431. [CrossRef]

61. Papageorgiou, G.Z.; Karandrea, E.; Giliopoulos, D.J.; Papageorgiou, D.G.; Ladavos, A.; Katerinopoulou, A.; Achilias, D.S.; Triantafyllidis, K.S.; Bikiaris, D.N. Effect of clay structure and type of organomodifier on the thermal properties of poly(ethylene terephthalate) based nanocomposites. Thermochim. Acta 2014, 576, 84-96. [CrossRef]

62. Thomas, D.G.; Staveley, L.A.K. 889. A study of the supercooling of drops of some molecular liquids. J. Chem. Soc. 1952, 4569-4577. [CrossRef]

63. Jeziorny, A. Parameters characterizing the kinetics of the non-isothermal crystallization of poly(ethylene terephthalate) determined by d.s.c. Polymer 1978, 19, 1142-1144. [CrossRef]

64. Di Lorenzo, M.; Silvestre, C. Non-isothermal crystallization of polymers. Prog. Polym. Sci. 1999, 24, 917-950. [CrossRef]

65. Guigo, N.; van Berkel, J.; de Jong, E.; Sbirrazzuoli, N. Modelling the non-isothermal crystallization of polymers: Application to poly (ethylene 2, 5-furandicarboxylate). Thermochim. Acta 2017, 650, 66-75. [CrossRef]

66. Avrami, M. Kinetics of phase change. I General theory. J. Chem. Phys. 1939, 7, 1103-1112. [CrossRef]

67. Formela, K.; Zedler, Ł.; Hejna, A.; Tercjak, A. Reactive extrusion of bio-based polymer blends and composites-Current trends and future developments. Express Polym. Lett. 2018, 12, 24-57. [CrossRef] 